\title{
Human papillomavirus genotyping for the eight oncogenic types can improve specificity of HPV testing in women with mildly abnormal Pap results
}

Ming Guo ${ }^{1}$, Ching-Yu Lin², Yun Gong ${ }^{1}$, David E Cogdell ${ }^{1}$, Wei Zhang ${ }^{1}$, E Lin ${ }^{3}$ and Nour Sneige ${ }^{1}$

${ }^{1}$ Department of Pathology, The University of Texas MD Anderson Cancer Center, Houston, TX, USA; ${ }^{2}$ School of Medical Laboratory Science and Biotechnology, Taipei Medical University, Taipei, Taiwan and

${ }^{3}$ Biostatistics and Applied Mathematics, The University of Texas MD Anderson Cancer Center, Houston, TX, USA

\begin{abstract}
To evaluate whether human papillomavirus (HPV) genotyping for the selected oncogenic HPV types can improve the efficacy of HPV DNA testing in predicting cervical intraepithelial neoplasia (CIN 2/3) in women with mildly abnormal Pap results, we compared HPV DNA testing and HPV genotyping for eight oncogenic types (16, 18, 31, 33, 35, 45, 52 and 58) in Pap specimens with abnormal results (HSIL, 20 cases; LSIL, 42 cases; ASC-US, 94 cases) and follow-up biopsies. Using consensus primer-mediated PCR assays, HPV DNA was detected in $90 \%(18 / 20)$ of HSIL, $95 \%$ (40/42) of LSIL and $64 \%$ (60/94) of ASC-US cases. HPV DNA positivity was significantly associated with CIN 2/3/carcinoma $(P<0.001)$ in women with ASC-US, but not in women with LSIL $(P=0.52)$. Of HPV DNA-positive specimens, the eight oncogenic HPV types were detected in $83 \%$ of HSIL cases (15/18), 53\% of LSIL cases (21/40), and $47 \%$ of ASC-US cases (28/60). The eight oncogenic HPV types were significantly associated with $\mathrm{CIN} 2 / 3 / \mathrm{carcinoma}(\mathrm{OR}, 10.6 ; 95 \% \mathrm{Cl}$, 3.98-28.10; $\boldsymbol{P}<0.001)$, whereas no significant association was observed between the non-eight oncogenic HPV types and CIN 2/3/carcinoma (OR, 2.20; 95\% $\mathrm{Cl}, 0.80-6.03$; $P=0.125)$. In women with ASC-US, HPV genotyping for the eight oncogenic types showed higher specificity (81 vs $46 \%$ ) and positive predictive value (PPV, 44 vs $26 \%$ ) in predicting CIN 2/3/carcinoma compared to HPV DNA testing. Similarly, in women with LSIL, higher specificity (69 vs $8 \%$ ) and PPV (62 vs $39 \%)$ for predicting CIN 2/3/carcinoma were also observed using HPV genotyping test for the eight oncogenic types compared to HPV DNA testing. Our findings suggested that HPV genotyping for the eight oncogenic types might be useful to improve the efficacy of HPV DNA testing for predicting CIN 2/3/carcinoma in women with mildly abnormal Pap results, which may lead to personalized clinical management with improved patient compliance for follow-up. Modern Pathology (2008) 21, 1037-1043; doi:10.1038/modpathol.2008.93; published online 23 May 2008
\end{abstract}

Keywords: human papillomavirus; HPV; genotyping; HSIL; LSIL; ASCUS

Oncogenic HPV infection has been recognized as a primary risk factor responsible for more than $99 \%$ of cervical carcinoma and high-grade cervical precancerous lesions, that is, CIN $2 / 3 .^{1}$ Persistent oncogenic HPV infection has been considered as the most important factor to determine cervical precancerous lesion progression. ${ }^{2,3}$ In the United States, HPV DNA

Correspondence: Dr M Guo, MD, Department of Pathology, Unit 58, The University of Texas MD Anderson Cancer Center, 1515 Holcombe Blvd, Houston, TX 77030-4009, USA.

E-mail:mguo@mdanderson.org

Received 14 February 2008; revised 09 April 2008; accepted 16 April 2008; published online 23 May 2008 testing in conjunction with Pap cytology test has become standard practice for patient management in gynecology clinics and cervical cancer prevention programs. ${ }^{4,5}$ Reflex oncogenic HPV DNA testing using pooled-probes has proved cost effective in the triage of women with atypical squamous cells of under-determined significance (ASC-US) ${ }^{6}$ Triage of women with low-grade squamous intraepithelial lesions (LSIL) using HPV DNA testing was recently recommended, but only for postmenopausal women. ${ }^{4}$ The reason that HPV DNA testing was not recommended initially in the triage of women with LSIL was that the positive rate of oncogenic HPV DNA testing was too high to allow a cost-effective 
triage. ${ }^{6}$ It has been well recognized that the advantage of HPV DNA testing using pooled-probes or consensus primer-mediated PCR assays is that a high clinical sensitivity in predicting CIN 2/3/ carcinoma in women with ASCUS can be achieved. With the high sensitivity and negative predictive value (NPV) of HPV DNA testing, women who have negative results plus a negative Pap test can be assured that they have little risk of having or developing CIN 2/3. However, these high sensitivity and NPV are achieved at the expense of lower specificity and lower positive predictive value (PPV). As a result, unnecessary colposcopy or biopsy may be done for women with an insignificant, transient oncogenic HPV infection. On the other hand, in women with significantly higher risks of developing CIN 2/3 or CIN progression, such as those with persistent HPV16 or 18 infections, a positive HPV DNA result without genotyping provides little information for a personalized management that requires closer clinical follow up and a high level of patient compliance. ${ }^{7}$

Although 14 HPV types have been recognized as the primary oncogenic HPV types responsible for the majority of cervical cancer and CIN $2 / 3,{ }^{8}$ evidences have shown significant variation of the carcinogenic potency among these oncogenic HPV types, with the highest risk in women who have persistent infection by HPV16. ${ }^{9}$ Recent epidemiologic studies have demonstrated that eight oncogenic HPV types (16, $18,31,33,35,45,52$ and 58 ) are responsible for more than $80 \%$ of cervical cancer and CIN 2/3. ${ }^{10,11}$ In particular, HPV types 16 and 18 were reported to be responsible for $70 \%$ of CIN $2 / 3 .{ }^{10}$ In cervical tissue specimens, we also confirmed that these eight oncogenic HPV types were significantly associated with CIN 2/3/carcinoma, whereas the other HPV types were not. ${ }^{12}$ Detecting the oncogenic HPV types with statistically higher associations with CIN 2/3/carcinoma and persistency could be clinically more relevant in predicting CIN 2/3 or CIN progression, ${ }^{13}$ and may improve specificity and PPV of HPV DNA testing.

To evaluate whether genotyping for the eight oncogenic HPV types can improve the specificity and PPV of HPV DNA testing, we compared the ability of consensus primer-mediated PCR HPV DNA testing and HPV genotyping to predict CIN $2 / 3$ in women with abnormal Pap results by comparing follow-up biopsies.

\section{Materials and methods}

The Institutional Review Board of The University of Texas MD Anderson Cancer Center approved the study.

\section{Cytology Specimen Selection}

Residual material from 156 cases of SurePath (TriPath Imaging, Burlington, NC, USA) Pap specimens with abnormal Pap results and follow-up biopsies were collected in consecutive order from 2004 to 2005 at the Department of Pathology, the University of Texas MD Anderson Cancer Center. The Pap specimens were screened by cytotechnologists and verified by cytopathologists following the Bethesda System. ${ }^{14}$ After the cytology diagnoses were completed, the Pap specimens were rinsed $(\times 2)$ and collected in RPMI medium 1640 (Gibco, Carlsbad, CA, USA), and stored at $-20^{\circ} \mathrm{C}$. The Pap specimens consisted of 20 cases of high-grade squamous intraepithelial lesions (HSIL), 42 cases of LSIL and 94 cases of ASC-US or atypical squamous cells, cannot exclude HSIL (ASC-H) The corresponding follow-up biopsies, processed and interpreted at the Department of Pathology, were performed either on the same day as or within 6 months of the Pap specimen collection. The biopsy results consisted of 29 cases of benign results, 77 cases of CIN1/koilocytosis, 41 cases of CIN $2 / 3$, and 9 cases of cervical carcinoma.

\section{DNA Extraction}

DNA was extracted from SurePath Pap specimens using the DNeasy kit (catalog no. 69506, Qiagen, Valencia, CA, USA) according to the manufacturer's instructions.

\section{HPV DNA Testing Using Consensus Primer-Mediated PCR}

Validation of PCR assays using GP5 + /GP6 + consensus primers in SurePath Pap specimens was reported. ${ }^{15}$ HPV DNA was determined using consensus primer-mediated PCR assays as described previously. ${ }^{12}$ Briefly, $\beta$-globin (268 bp) was amplified to determine the quality of the extracted DNA using primer sets pc04/gh20 according to Bauer et $a l^{16}$ and using AmpliTaq Gold polymerase (Applied Biosystems, Foster City, CA, USA). A 25-ng aliquot of genomic DNA was added to a PCR master mixture containing $1 \times$ PCR buffer $(100 \mathrm{mM}$ Tris-HCl, $500 \mathrm{mM} \mathrm{KCl,} \mathrm{pH} \mathrm{8.3),} 200 \mu \mathrm{M}$ concentrations of each deoxynucleoside triphosphate, $200 \mathrm{nM}$ primer, $1.5 \mathrm{mM} \mathrm{MgCl}_{2}$, and 2.5 units of AmpliTaq Gold DNA polymerase. PCR was performed under the following permissive cycling conditions: $10 \mathrm{~min}$ at $94^{\circ} \mathrm{C}$, followed by $1 \mathrm{~min}$ at $94^{\circ} \mathrm{C}, 1 \mathrm{~min}$ at $40^{\circ} \mathrm{C}$, $90 \mathrm{~s}$ at $72^{\circ} \mathrm{C}$, and $5 \mathrm{~min}$ at $72^{\circ} \mathrm{C}$ for 39 cycles.

Specimens positive for $\beta$-globin were screened for HPV DNA using GP5 + /GP6 + consensus primermediated PCR, which generates 150-bp amplicons. PCR was performed according to the method of Jacobs et al. ${ }^{17}$ A 25-ng aliquot of genomic DNA was added to the PCR master mixture, which contained $1 \times$ PCR buffer, $200 \mu \mathrm{M}$ concentrations of each deoxynucleoside triphosphate, $200 \mathrm{nM}$ primers, $3.5 \mathrm{mM} \mathrm{MgCl}_{2}$, and 2.5 units of AmpliTaq Gold DNA polymerase. The cycling condition was the same as those for $\beta$-globin. Specimens that were 
positive for $\beta$-globin but negative for GP5 + /GP6 + were re-screened for HPV DNA with the second consensus primer set (PGMY09/11), which generates $450 \mathrm{bp}$ amplicons. A 25-ng aliquot of genomic DNA was used for amplification in a PCR master mixture containing $1 \times$ PCR buffer, $200 \mu \mathrm{M}$ concentrations of each deoxynucleoside triphosphate, $200 \mathrm{nM}$ primer, $4.0 \mathrm{mM} \mathrm{MgCl}_{2}$, and 7.5 units of AmpliTaq Gold DNA polymerase. The PCR was performed under the following cycling conditions: $9 \mathrm{~min}$ at $94^{\circ} \mathrm{C}$, followed by $1 \mathrm{~min}$ at $94^{\circ} \mathrm{C}, 1 \mathrm{~min}$ at $55^{\circ} \mathrm{C}$, and $1 \mathrm{~min}$ at $72^{\circ} \mathrm{C}$ for 39 cycles. Specimens with known HPV infection were used as positive controls. Sterile water was used as a negative control for each set of amplifications. The PCR products were visualized with ethidium bromide staining on a $4 \%$ low-melt agarose gel.

\section{HPV Genotyping by EasyChip HPV Blot}

Specimens with positive results on consensus primer-mediated PCR were genotyped using EasyChip HPV Blot (King Car Yuanshan Research Institute, I-Lan, Taiwan) as described previously. ${ }^{18}$ First, HPV DNA was amplified by PCR assay using modified MY11/GP6 + biotinylated consensus primer sets to amplify a fragment of $192 \mathrm{bp}$ in the L1 open reading frame of HPV and GAPDHF/GAPDHR biotinylated primer sets were used to amplify a 136-bp segment for specimen validation as described previously. ${ }^{4,19}$ Briefly, PCR for HPV DNA was performed in a final reaction volume of $26 \mu \mathrm{l}$ with 20-ng aliquot of genomic DNA in a PCR master mixture containing $15 \mathrm{mM}$ Tris-HCl $(\mathrm{pH}$ 8.0), $2.0 \mathrm{mM} \mathrm{MgCl}_{2}, 50 \mathrm{mM} \mathrm{KCl}, 0.25 \mathrm{mM}$ each deoxynucleoside triphosphate, $0.6 \mu \mathrm{M}$ primer, and 0.5 units of DNA polymerase $\left(\mathrm{HP}^{\mathrm{TM}}\right.$ High Performance HotStart Taq DNA Polymerase; DNA Technologies Ltd., UK). PCR assay was performed as follows: $10 \mathrm{~min}$ at $95^{\circ} \mathrm{C}$, followed by 40 cycles of $30 \mathrm{~s}$ at $95^{\circ} \mathrm{C}$, $30 \mathrm{~s}$ at $45^{\circ} \mathrm{C}$, and $30 \mathrm{~s}$ at $72^{\circ} \mathrm{C}$ and a final extension of $5 \mathrm{~min}$ at $72^{\circ} \mathrm{C}$. PCR for GAPDH was performed in a final reaction volume of $25 \mu \mathrm{l}$ with a 10-ng aliquot of genomic DNA in a PCR master mixture containing $15 \mathrm{mM}$ Tris-HCl (pH 8.0), $2.5 \mathrm{mM} \mathrm{MgCl}_{2}, 50 \mathrm{mM} \mathrm{KCl}$, $0.2 \mathrm{mM}$ each deoxynucleoside triphosphate, $0.2 \mu \mathrm{M}$ primer, and 0.5 units of HotStart Taq DNA Polymerase (DNA Technologies Ltd., UK). PCR assay was performed as follows: $10 \mathrm{~min}$ at $95^{\circ} \mathrm{C}$, followed by 40 cycles of $15 \mathrm{~s}$ at $95^{\circ} \mathrm{C}, 1 \mathrm{~min}$ at $57^{\circ} \mathrm{C}$, and $30 \mathrm{~s}$ at $72^{\circ} \mathrm{C}$ and a final extension of $5 \mathrm{~min}$ at $72^{\circ} \mathrm{C}$. A $5-\mu \mathrm{l}$ aliquot of PCR products was analyzed by electrophoresis on a $2 \%$ agarose gel and stained with ethidium bromide.

EasyChip HPV blot were designed to detect 39 HPV types (HPV 6, 11, 16, 18, 26, 31, 32, 33, 35, 37, $39,42,43,44,45,51,52,53,54,55,56,58,59,61$, 62, 66, 67, 68, 69, 70, 72, 74, 82, CP8061, CP8304, L1AE5, MM4, MM7 and MM8 as well as three intrinsic controls). The HPV type-specific probes were immobilized on a $14.4 \times 9.6 \mathrm{~mm}$ nylon membrane, which was used for reverse-blot hybridization to detect HPV DNA in a single assay. The hybridization was performed according to the manufacturer's instructions. Briefly, the blot membrane was equilibrated with $2 \times$ saline-sodium citrate (SCC, $1 \times$ SCC containing $0.15 \mathrm{M} \mathrm{NaCl}$ and $0.015 \mathrm{M}$ sodium citrate) at room temperature for $10 \mathrm{~min}$. The blot was preincubated in hybridization buffer $(2 \times$ SSC, $0.5 \%$ blocking reagent, $5 \%$ dextran sulfate, $0.1 \%$ sodium dodecyl sulfate (SDS), $50 \mu \mathrm{g} / \mathrm{ml}$ denatured salmon sperm DNA) with shaking at $35^{\circ} \mathrm{C}$ for $30 \mathrm{~min}$. The membrane was hybridized with $500 \mu \mathrm{l}$ of hybridization buffer containing $20 \mu \mathrm{l}$ of the denatured amplicons (15 $\mu \mathrm{l}$ HPV and $5 \mu \mathrm{l}$ GAPDH PCR products) by shaking at $35^{\circ} \mathrm{C}$ for at least $3 \mathrm{~h}$. The blot was washed two times in washing buffer $1(2 \times$ SSC, $0.1 \%$ SDS $)$ for $5 \mathrm{~min}$ at $25^{\circ} \mathrm{C}$ and then washed two times in washing buffer $2(0.2 \times$ SSC, $0.1 \%$ SDS $)$ for $5 \mathrm{~min}$ at $35^{\circ} \mathrm{C}$. The blot was equilibrated with buffer 1 $(1 \times$ phosphate-buffered saline, $\mathrm{pH} 7.4, \quad 0.05 \%$ Tween $20,0.1 \%$ SDS) by shaking at $25^{\circ} \mathrm{C}$ for $5 \mathrm{~min}$ and then buffer $2(1 \times$ phosphate-buffered saline, $\mathrm{pH} 7.4,0.05 \%$ Tween $20,0.1 \%$ SDS, $0.5 \%$ blocking reagent) at $25^{\circ} \mathrm{C}$ for $1 \mathrm{~h}$. The blot was incubated in $500 \mu \mathrm{l}$ of buffer 2 containing streptavidin-AP (Calbiochem; alkaline phosphatase conjugates and biotinylated antibodies, 1:1000 dilution) at $25^{\circ} \mathrm{C}$ for $40 \mathrm{~min}$. The blot was then washed in buffer 1 and rinsed with buffer 3 (0.1 M Tris-HCl, $\mathrm{pH} 9.5,0.1 \mathrm{M}$ $\mathrm{NaCl}$ ) for $5 \mathrm{~min}$. Then, $80 \mu \mathrm{l} \mathrm{NBT/BCIP} \mathrm{(5-bromo-}$ chloro-3-indolyl-phospate and nitroblue tetrazolium) was added and incubated for $30 \mathrm{~min}$ at $25^{\circ} \mathrm{C}$. The reaction was terminated by adding distilled water. The HPV types were determined by visual assessment protocol provided by King Car Yuanshan Research Institute.

\section{Statistical Analysis}

Descriptive statistics were calculated; KruskalWallis tests were used to compare the differences among groups of continuous variables; $\chi^{2}$ or Fisher's exact tests were used to assess the association between categorical variables; Cohran-Armitage trend tests or Jonckheere-Terpstra tests were used to assess the association between test results and severity of disease; Logistic regression models were used to estimate the odds ratios of cancer $\geq$ CIN2, including 95\% confidence intervals. $P$-values (twosided test) of less than 0.05 were considered significant. All computations were carried out using SAS 8.0 (SAS Institute, Cary, NC, USA).

\section{Results}

The age of the patients in the study ranged from 19 to 85 years, with a mean age of 43 years and a median age of 44 years. The distribution of race was as follows: Caucasian, 116; Hispanic, 23; Africa 
Table 1 Distribution of HPV DNA and follow-up biopsy results in Surepath Pap specimens

\begin{tabular}{|c|c|c|c|c|c|}
\hline \multirow[t]{2}{*}{ Cytology } & \multirow[t]{2}{*}{$H P V(\%)$} & \multicolumn{3}{|c|}{ Biopsy } & Tota \\
\hline & & $\leq C I N 1$ & CIN2/3 & Carcinoma & \\
\hline HSIL & $18 / 20(90)$ & 0 & 15 & 5 & 20 \\
\hline LSIL & 40/42 (95) & 27 & 14 & 1 & 42 \\
\hline ASC-US/ASC-H & 60/94 (64) & 79 & 12 & 3 & 94 \\
\hline
\end{tabular}

American, 11 and Asian, 6. The distribution of the follow up biopsy results with corresponding Pap specimens is illustrated in Table 1. In 20 cases of SurePath Pap specimens with HSIL results, the follow-up biopsies showed either carcinoma (five cases) or CIN 2/3 (15 cases). In 42 Pap specimens with LSIL results, the follow-up biopsies showed 14 cases $(33 \%, 14 / 42)$ with lesion $\geq$ CIN2 (one case of carcinoma, 13 cases of CIN 2/3) and 28 cases of CIN 1/koilocytosis/benign. In $94 \mathrm{Pap}$ specimens with ASC-US/ASC-H, the follow-up biopsies showed 15 cases $(14 \%, 15 / 94)$ with lesion $\geq$ CIN2 (three cases of carcinoma, 12 cases of CIN 2/3) and 79 cases of CIN1/koilocytosis/benign (Table 1).

\section{Distribution of HPV DNA and Oncogenic HPV Genotypes in SurePath Pap Specimens and Comparison with the Follow-up Biopsies}

HPV DNA was positive in $90 \%(18 / 20)$ of HSIL cases (Table 1). Of 18 specimens with HSIL/HPV DNA +, $83 \%(15 / 18)$ showed positive results with at least one of the eight oncogenic HPV types. In the remaining three cases, one showed HPV51/42. The other two Pap specimens showed HPV 82. In Pap specimens with LSIL results, 95\% (40/42) were HPV DNA positive. HPV DNA was positive in all 14 Pap specimens with CIN 2/3/carcinoma biopsy results. Of 28 cases with CIN1/benign biopsy results, 93\% (26/28) of specimens were positive for HPV DNA. No significant association of HPV DNA positivity with CIN $2 / 3 /$ carcinoma $(P=0.52)$ was observed (Table 2). The eight oncogenic HPV types were positive in $86 \%(12 / 14)$ of Pap specimens with CIN $2 / 3 /$ carcinoma biopsy results. Only $32 \%(9 / 28)$ of Pap specimens with CIN1/benign biopsy results were positive for the eight oncogenic HPV types. The eight oncogenic HPV types were significantly associated with CIN 2/3/carcinoma $(P<0.0001)$ (Table 2). Two Pap specimens with CIN 2 biopsy results showed non-eight HPV types, one with HPV 68/6 and another with HPV 66/53/56.

In the ASCUS/ASC-H group, 64\% (60/94) of cases were positive for HPV DNA. HPV DNA was positive in all 15 Pap specimens with CIN 2/3/ carcinoma biopsy results. In 79 Pap specimens with CIN1/benign biopsy results, HPV DNA was positive in $57 \%(45 / 79)$ cases. HPV DNA positivity in Pap specimens with ASC-US/ASC-H was signifi-
Table 2 Comparison of HPV DNA, the eight oncogenic HPV types and follow-up biopsy in Surepath Pap specimens with LSIL

\begin{tabular}{|c|c|c|c|c|}
\hline \multirow[t]{2}{*}{ Biopsy } & \multicolumn{2}{|c|}{$H P V D N A$} & \multicolumn{2}{|c|}{ Eight types } \\
\hline & $(-)$ & $(+)$ & $(-)$ & $(+)$ \\
\hline$\leq \mathrm{CIN} 1$ & 2 & 26 & 19 & 9 \\
\hline$\geq \mathrm{CIN} 2$ & 0 & 14 & 2 & 12 \\
\hline Total & 2 & 40 & 21 & 21 \\
\hline$P$-value & \multicolumn{2}{|c|}{0.52} & \multicolumn{2}{|c|}{$<0.0001$} \\
\hline
\end{tabular}

Table 3 Comparison of HPV DNA, the eight oncogenic HPV types and follow-up biopsy in Surepath Pap specimens with ASCUS/ASC-H

\begin{tabular}{|c|c|c|c|c|}
\hline \multirow[t]{2}{*}{ Biopsy } & \multicolumn{2}{|c|}{$H P V D N A$} & \multicolumn{2}{|c|}{ Eight types } \\
\hline & $(-)$ & $(+)$ & $(-)$ & $(+)$ \\
\hline$\leq \mathrm{CIN} 1$ & 34 & 45 & 63 & 16 \\
\hline$\geq$ CIN2 & 0 & 15 & 3 & 12 \\
\hline Total & 34 & 60 & 66 & 28 \\
\hline$P$-value & \multicolumn{2}{|c|}{$<0.0001$} & \multicolumn{2}{|c|}{$<0.0001$} \\
\hline
\end{tabular}

cantly associated with CIN 2/3/carcinoma results $(P<0.0001)$. The eight HPV types were positive in $80 \%(12 / 15)$ of Pap specimens with CIN 2/3/ carcinoma biopsy results, whereas only $20 \%(16 / 79)$ of Pap specimens with CIN1/benign biopsy results were positive for the eight oncogenic HPV types. Significant association of the eight oncogenic HPV types with CIN 2/3/carcinoma was observed $(P<0.0001)$ (Table 3). Three Pap specimens with CIN 2/3/carcinoma biopsy results were positive for non-eight HPV types, one case of cervical carcinoma with HPV 55/72, one case of CIN 2/3 with HPV 56 and the other case of CIN 2/3 with HPV 39/42/43.

HPV16 and HPV18 positive rates in the Pap specimens with CIN 2/3/carcinoma were $56 \%$ $(10 / 18)$ in HSIL cases, $57 \%(8 / 14)$ in LSIL cases, and $60 \%(9 / 15)$ in ASC-US/ASC-H cases. Multiple HPV infections in the Pap specimens with CIN 2/3/carcinoma biopsy results were predominantly observed in HSIL $(89 \%, 16 / 18)$ and LSIL cases (93\%, 13/14), compared with ASC-US/ASC-H cases $(40 \%, 6 / 15)$.

\section{Comparison of HPV DNA and HPV Genotyping for the Eight Oncogenic HPV Types in Predicting CIN 2/3/ Carcinoma in Pap Specimens with Mild Abnormalities}

Using a univariate logistic regression model to estimate the association between HPV types and all Pap specimens with CIN 2/3/carcinoma biopsy results, the eight oncogenic HPV types showed a significant association with the CIN 2/3/carcinoma (OR, 10.6; $95 \%$ CI, 3.98-28.10, $P$-value <0.001). No significant association of non-eight HPV types with the diseases was observed (OR, 2.20; 95\% CI, 0.80-6.03; $P$-value $=0.125)$. 
Table 4 The Efficacy of HPV DNA testing, genotyping for the eight oncogenic HPV types in women with ASCUS

\begin{tabular}{lcccc}
\hline $\begin{array}{l}\text { HPV } \\
\text { testing }\end{array}$ & $\begin{array}{c}\text { Sensitivity } \% \\
\text { (95\% CI, } \\
\text { upper) }\end{array}$ & $\begin{array}{c}\text { Specificity } \% \\
\text { (95\% CI, } \\
\text { upper) }\end{array}$ & $\begin{array}{c}\text { PPV \% } \\
\text { (95\% CI, } \\
\text { upper) }\end{array}$ & $\begin{array}{c}\text { NPV \% } \\
\text { (95\% CI, } \\
\text { upper) }\end{array}$ \\
\hline HPV DNA & $100(100)$ & $46(57)$ & $26(39)$ & $100(100)$ \\
Eight types & $80(96)$ & $81(89)$ & $44(65)$ & $96(99)$ \\
\hline
\end{tabular}

Table 5 The Efficacy of HPV DNA testing and genotyping for the eight oncogenic HPV types in women with LSIL

\begin{tabular}{|c|c|c|c|c|}
\hline $\begin{array}{l}H P V \\
\text { testing }\end{array}$ & $\begin{array}{c}\text { Sensitivity \% } \\
\text { (95\% CI, } \\
\text { upper) }\end{array}$ & $\begin{array}{c}\text { Specificity \% } \\
\text { (95\% CI, } \\
\text { upper) }\end{array}$ & $\begin{array}{c}P P V \% \\
\text { (95\% CI, } \\
\text { upper) }\end{array}$ & $\begin{array}{c}\text { NPV \% } \\
\text { (95\% CI, } \\
\text { upper) }\end{array}$ \\
\hline HPV DNA & $100(100)$ & $8(25)$ & $39(55)$ & $100(100$ \\
\hline Eight types & 87 (98) & $69(86)$ & $62(82)$ & 90 (98) \\
\hline
\end{tabular}

In ASCUS/ASC-H group, a high sensitivity $(100 \%)$ and a high NPV $(100 \%)$ to predict CIN 2/3/carcinoma were observed using HPV DNA testing. The specificity and PPV were 46 and $26 \%$, respectively (Table 4). The specificity and PPV were significantly improved using genotyping for the eight oncogenic HPV types (specificity, 46 vs $81 \%$; PPV, 26 vs 44\%) (Table 4). The univariate logistic regression model showed the highest risk association between HPV16/18 and CIN 2/3/carcinoma (OR, 20.0; 95\% CI, 4.19-95.48). The risk association decreased when all the eight oncogenic HPV types were estimated (OR, 6.75; 95\% CI: 1.65-27.59).

In LSIL group, HPV DNA testing also showed high sensitivity (100\%) and NPV (100\%) with low specificity ( $8 \%$ ) and PPV (39\%). With genotyping for the eight oncogenic HPV types, significant improvements in specificity (eight vs 69\%) and PPV (39 vs $62 \%$ ) were observed (Table 5). The risk association of HPV16/18 is also higher (OR, 13.8; 95\% CI: 2.7-70.12) than that of the combined eight oncogenic HPV types (OR, 11.3; 95\% CI: 2.07-62.10).

Compared with HPV DNA testing, HPV genotyping for the eight oncogenic HPV types showed lower sensitivity and NPV in both the ASCUS (80, 96\%) and LSIL group (87, 90\%) (Tables 4 and 5).

\section{Discussion}

In this study, we demonstrated that genotyping for the eight major oncogenic HPV types can significantly improve specificity and PPV of HPV DNA testing to predict CIN 2/3/carcinoma in women with mildly abnormal Pap results, indicating HPV genotyping has potential utilization for risk assessment and personalized clinical management in cervical cancer prevention.

Evidence has shown that HPV genotyping may play an important role in cervical cancer prevention., , $^{2,20-23}$ However, how to utilize HPV genotyping in patient management is still under investigation, partly due to the complexity of oncogenic HPV types with wide ranges of oncogenic potential and frequent multiple oncogenic HPV infections in the cervical precancer lesions, making it difficult to determine which oncogenic HPV types should be given a priority in predicting CIN 2/3 or CIN progression. Epidemiology studies and our previous observations in cervical tissue specimens demonstrated that the eight major oncogenic HPV types, HPV16, 18, 31, 33, $35,45,52$ and 58 , are closely associated with CIN $2 / 3$ and cervical carcinoma, collectively accounting for more than $80 \%$ of cervical carcinoma and CIN $2 / 3 .{ }^{10-12}$ Of these eight types, HPV16 and 18 are the most clinically relevant HPV types. ${ }^{10,21}$ In our study using Pap cytology specimens, we confirmed that HPV16 and 18 had the highest association with CIN $2 / 3$ /carcinoma in women with LSIL or ASCUS. HPV16/18 were positive in $75 \%$ of Pap specimens with either LSIL (OR, 13.8; 95\% CI, 2.70-70.12) or ASCUS (OR, 20; 95\% CI, 4.19-95.48) that had CIN $2 / 3 /$ carcinoma biopsy results. These findings are in keeping with the recently published studies from the ALTS trial that clearly demonstrated high-risk of cervical precancerous lesion progression in women with mildly abnormal Pap results and positive HPV16/18 results. ${ }^{9,23}$ The clinical significance of HPV16/18 in women with mildly abnormal Pap results is probably due to the persistence of HPV16/ $18 .^{24}$ Our observation and published studies indicated that at least HPV16/18 should be given a priority for predicting CIN 2/3/carcinoma in women with mildly abnormal Pap results. Compared to HPV16/18, the other six oncogenic HPV types (31, $33,35,45,52$ and 58) had a lower association with CIN 2/3/carcinoma. Although we were not able to determine the risk level for these six oncogenic HPV types because of frequent co-infection with HV16/18, decreased risk levels were observed in both ASCUS and LSIL when all the eight oncogenic HPV types including HPV16/18 were calculated collectively. This finding is in agreement with the recently published study that demonstrated HPV16 had the highest cumulative risk, that dominated the risk of other oncogenic HPVs in women with ASCUS or LSIL. ${ }^{21}$ Nevertheless, using the eight major oncogenic HPV types as a cutoff, the specificity and PPV in detecting CIN 2/3 in women with mildly abnormal Pap results were significantly improved compared to those of using the full range of HPV DNA. The positivity of HPV DNA in our ASCUS/ASC-H group was comparable to that of ALTS trial study ${ }^{6}$ and was significantly associated with CIN 2/3/carcinoma with $100 \%$ sensitivity and NPV for CIN 2/3/carcinoma, respectively. With HPV genotyping for the eight oncogenic types, specificity was significantly improved from 46 to $81 \%$. In our LSIL group, however, since the majority of Pap specimens were positive for HPV DNA, no significant association between HPV DNA and CIN 2/3/ carcinoma was observed in women with LSIL. This 
finding is also consistent with those in the ALTS trial, which concluded that HPV DNA testing cannot be used efficiently in the triage of women with LSIL. ${ }^{6}$ With HPV genotyping for the eight oncogenic types, the specificity was increased from eight to $69 \%$, suggesting that HPV genotyping with the eight oncogenic types might have potential for predicting CIN 2/3/carcinoma in women with LSIL. As our study only had one-time HPV genotyping test, the persistence of HPV infection could not be determined. Further studies on the persistent infection with the eight oncogenic HPV is necessary to determine whether the persistent infection can further improve the specificity of HPV DNA testing for women with ASCUS or LSIL. The goal would be a more personalized clinical management that can reduce unnecessary colposcopic/biopsy follow up and at the same time increase patient compliance to allow closer follow up for those with the highest risk of CIN progression.

On the basis of the epidemiologic studies, 14 oncogenic HPV types (HPV16, 18, 31, 33, 35, 45, 51, $52,56,58,59,66$ and 68) are classified as the oncogenic types responsible for cervical carcinoma and precancerous lesions. ${ }^{8,25}$ In our study, a total of eight Pap specimens (three HSIL cases, two LSIL cases and three ASCUS cases) with CIN 2/3/carcinoma biopsy results tested positive for HPV types other than the eight major HPV oncogenic types. Recently, a reduction in the number of oncogenic HPV types for cervical cancer from 14 to 12 was proposed: Along with HPV 26, 73 and 82, HPV 66 and 68 could be reclassified as possible oncogenic types. ${ }^{26}$ According to this newly proposed classification, our study identified only three Pap specimens with CIN 2/3 biopsy results as positive for the non-eight oncogenic HPV types (one case each with HPV39 or 56 from ASCUS, one case with HPV51 from LSIL). Four cases with CIN 2/3 biopsy results were positive for HPV types that are possibly oncogenic (one case each for HPV 66 or 68 from LSIL, two cases for HPV 82 from HSIL). Only one ASCUS case with carcinoma biopsy result was positive for HPV types that are not currently classified as oncogenic, that is, HPV55/72. Owing to limited CIN 2/3 case numbers and the lack of convincing evidence for the oncogenic potencies of these possible oncogenic HPV types, it is unclear whether cervical precancerous lesions in women who have infections with these HPV types will be more likely to progress or regress. Since persistent type-specific HPV infection is one of the most important factors in the progression of CIN lesions, ${ }^{27}$ a determination of HPV persistency by genotyping might clarify their oncogenic potencies and better guide follow-up of these patients. ${ }^{28}$

It has been recognized that all traditional cervical cancer detection modalities, Pap test, colposcopy and biopsy, have limitations in predicting CIN 2/3. ${ }^{29-31}$ HPV DNA testing has added considerable value to current cervical cancer prevention programs because of its ability to predict CIN $2 / 3 .^{32-34}$ According to the recently proposed personalized risk profiling for cervical cancer prevention, the predictive level for CIN 2/3 can be assessed using a combination of Pap testing, HPV testing, and colposcopy/biopsy evaluation. ${ }^{35}$ The patients may be managed or treated based on their risk profiles. Our study provides evidence that selective HPV genotyping would add improved accuracy of the risk profiling. With HPV genotyping data, risk profiling may become more specific, thus facilitating highly personalized clinical management and improved patient compliance.

Our study was conducted in a cancer center with a population that is older than a general screening population. Therefore, we cannot exclude the possibility that age contributed to the high specificity of HPV genotyping in predicting CIN 2/3 in our study. A recent study demonstrated that older women were more likely to have a persistent HPV infection than younger women, although most infections by the oncogenic HPV types cleared in 2 years. ${ }^{36}$ Therefore, with an older age group, our observation of the high specificity of the eight oncogenic HPV types to predict CIN 2/3 in women with mildly abnormal Pap test might be associated with higher frequency of oncogenic HPV persistency. Further studies with age-stratified cohorts are necessary to clarify this issue. To date, HPV genotyping assays have not been approved for patient care by FDA. Furthermore, the cost effectiveness of using HPV genotyping to predict cervical precancerous lesions has not been evaluated. Clinical trials with large patient base are necessary to prove the potential utilization and the cost effectiveness of HPV genotyping in patient management.

\section{Acknowledgements}

The study was supported by the University of Texas MD Anderson Cancer Center, Houston TX, USA. We thank King Car Yuanshan Research Institute, I-Lan, Taiwan, for providing EasyChip HPV Blot and technical support for HPV genotyping. We also thank Mr Walter J Pagel, the Department of Scientific Publications, MD Anderson Cancer Center, for editing the article.

\section{Conflict of interest}

The authors have no financial interests with any commercial products mentioned in this article.

\section{References}

1 Walboomers JM, Jacobs MV, Manos MM, et al. Human papillomavirus is a necessary cause of invasive cervical cancer worldwide. J Pathol 1999;189:12-19.

2 Khan MJ, Castle PE, Lorincz AT, et al. The elevated 10-year risk of cervical precancer and cancer in women with human papillomavirus (HPV) type 16 or 18 and 
the possible utility of type-specific HPV testing in clinical practice. J Natl Cancer Inst 2005;97:1072-1079.

3 Schiffman M, Herrero R, Desalle R, et al. The carcinogenicity of human papillomavirus types reflects viral evolution. Virology 2005;337:76-84.

4 Wright Jr TC, Massad LS, Dunton CJ, et al. 2006 consensus guidelines for the management of women with abnormal cervical cancer screening tests. Am J Obstet Gynecol 2007;197:346-355.

5 Wright Jr TC, Massad LS, Dunton CJ, et al. 2006 consensus guidelines for the management of women with cervical intraepithelial neoplasia or adenocarcinoma in situ. Am J Obstet Gynecol 2007;197:340-345.

6 Solomon D, Schiffman M, Tarone R. Comparison of three management strategies for patients with atypical squamous cells of undetermined significance: baseline results from a randomized trial. J Natl Cancer Inst 2001;93:293-299.

7 Castle PE. The potential utility of HPV genotyping in screening and clinical management. J Natl Compr Canc Netw 2008;6:83-95.

8 Munoz N, Bosch FX, de Sanjose S, et al. Epidemiologic classification of human papillomavirus types associated with cervical cancer. N Engl J Med 2003;348: 518-527.

9 Castle PE, Solomon D, Schiffman M, et al. Human papillomavirus type 16 infections and 2-year absolute risk of cervical precancer in women with equivocal or mild cytologic abnormalities. J Natl Cancer Inst 2005;97:1066-1071.

10 Clifford GM, Smith JS, Plummer M, et al. Human papillomavirus types in invasive cervical cancer worldwide: a meta-analysis. Br J Cancer 2003;88:63-73.

11 Clifford GM, Smith JS, Aguado T, et al. Comparison of HPV type distribution in high-grade cervical lesions and cervical cancer: a meta-analysis. Br J Cancer 2003; 89:101-105.

12 Guo M, Sneige N, Silva EG, et al. Distribution and viral load of eight oncogenic types of human papillomavirus (HPV) and HPV 16 integration status in cervical intraepithelial neoplasia and carcinoma. Mod Pathol 2007;20:256-266.

13 Rodriguez AC, Schiffman M, Herrero R, et al. Rapid clearance of human papillomavirus and implications for clinical focus on persistent infections. J Natl Cancer Inst 2008;100:513-517.

14 Solomon D, Davey D, Kurman R, et al. The 2001 Bethesda System: terminology for reporting results of cervical cytology. JAMA 2002;287:2114-2119.

15 Gillio-Tos A, De Marco L, Ghisetti V, et al. Human papillomavirus typing with GP5+/6+ polymerase chain reaction reverse line blotting and with commercial typespecific PCR kits. J Clin Virol 2006;36:126-132.

16 Bauer HM, Ting Y, Greer CE, et al. Genital human papillomavirus infection in female university students as determined by a PCR-based method. JAMA 1991; 265:472-477.

17 Jacobs MV, Snijders PJ, van den Brule AJ, et al. A general primer GP5+/GP6(+)-mediated PCR-enzyme immunoassay method for rapid detection of 14 highrisk and 6 low-risk human papillomavirus genotypes in cervical scrapings. J Clin Microbiol 1997;35:791-795.

18 Lin CY, Chen HC, Lin RW, et al. Quality assurance of genotyping array for detection and typing of human papillomavirus. J Virol Methods 2007;140:1-9.

19 Huang LW, Chao SL, Chen PH, et al. Multiple HPV genotypes in cervical carcinomas: improved DNA detection and typing in archival tissues. J Clin Virol 2004;29:271-276.

20 Zuna RE, Allen RA, Moore WE, et al. Distribution of HPV genotypes in 282 women with cervical lesions: evidence for three categories of intraepithelial lesions based on morphology and HPV type. Mod Pathol 2007;20:167-174.

21 Wheeler CM, Hunt WC, Schiffman M, et al. Human papillomavirus genotypes and the cumulative 2-year risk of cervical precancer. J Infect Dis 2006;194: 1291-1299.

22 Atkins KA, Jeronimo J, Stoler MH. Description of patients with squamous cell carcinoma in the atypical squamous cells of undetermined significance/lowgrade squamous intraepithelial lesion triage study. Cancer 2006;108:212-221.

23 Kovacic MB, Castle PE, Herrero R, et al. Relationships of human papillomavirus type, qualitative viral load, and age with cytologic abnormality. Cancer Res 2006;66:10112-10119.

24 Bulkmans NW, Berkhof J, Bulk S, et al. High-risk HPV type-specific clearance rates in cervical screening. Br J Cancer 2007;96:1419-1424.

25 Cogliano V, Baan R, Straif K, et al. Carcinogenicity of human papillomaviruses. Lancet Oncol 2005;6:204.

26 Munoz N, Castellsague X, de Gonzalez AB, et al. Chapter 1: HPV in the etiology of human cancer. Vaccine 2006;24S3:S1-S10.

27 Kjaer SK, van den Brule AJ, Paull G, et al. Type specific persistence of high risk human papillomavirus (HPV) as indicator of high grade cervical squamous intraepithelial lesions in young women: population based prospective follow up study. BMJ 2002;325:572.

28 Naucler P, Ryd W, Tornberg S, et al. HPV type-specific risks of high-grade CIN during 4 years of follow-up: a population-based prospective study. $\mathrm{Br} \mathrm{J}$ Cancer 2007;97:129-132.

29 Jeronimo J, Schiffman M. Colposcopy at a crossroads. Am J Obstet Gynecol 2006;195:349-353.

30 Adams AL, Eltoum I, Roberson J, et al. Negative colposcopic biopsy after positive human papilloma virus (HPV) DNA testing: false-positive HPV results or false-negative histologic findings? Am J Clin Pathol 2006;125:413-418

31 Cuzick J, Clavel C, Petry KU, et al. Overview of the European and North American studies on HPV testing in primary cervical cancer screening. Int J Cancer 2006;119:1095-1101.

32 Kjaer S, Hogdall E, Frederiksen K, et al. The absolute risk of cervical abnormalities in high-risk human papillomavirus-positive, cytologically normal women over a 10-year period. Cancer Res 2006;66:10630-10636.

33 Naucler P, Ryd W, Tornberg S, et al. Human papillomavirus and Papanicolaou tests to screen for cervical cancer. N Engl J Med 2007;357:1589-1597.

34 Bulkmans NW, Berkhof J, Rozendaal L, et al. Human papillomavirus DNA testing for the detection of cervical intraepithelial neoplasia grade 3 and cancer: 5-year follow-up of a randomised controlled implementation trial. Lancet 2007;370:1764-1772.

35 Castle PE, Sideri M, Jeronimo J, et al. Risk assessment to guide the prevention of cervical cancer. Am J Obstet Gynecol 2007;197:356 e1-6.

36 Castle PE, Schiffman M, Herrero R, et al. A prospective study of age trends in cervical human papillomavirus acquisition and persistence in Guanacaste, Costa Rica. J Infect Dis 2005;191:1808-1816. 